\title{
Dez espécies novas e notas sobre Rhabdepyris Kieffer (Hymenoptera, Bethylidae) da Mata Atlântica
}

\author{
Wesley L. Rosmann ${ }^{1} \&$ Celso O. Azevedo ${ }^{2,3}$
}

${ }^{1}$ PPG-Biologia Animal, Universidade Federal do Espírito Santo, Av. Marechal Campos 1468, 29.040-090 Vitória-ES, Brasil.

wrosmann@click21.com.br.

²Departamento de Biologia, Universidade Federal do Espírito Santo, bethylidae@gmail.com

${ }^{3}$ Pesquisador do CNPq.

\begin{abstract}
Ten new species and notes on Rhabdepyris (Hymenoptera, Bethylidae) of Atlantic Rain Forest. Rhabdepyris (Chlorepyris) atlanticus sp. nov., $R$. (C.) circinnatus sp. nov., $R$. (C.) clavatus sp. nov., $R$. (C.) ocultatus sp. nov., $R$. (C.) subangulatus sp. nov., $R$. (C.) sulcatus sp. nov., $R$. (C.) unifoveatus sp. nov., $R$. (R.) areolatus sp. nov., $R$. (Trichotepyris) curvicarinatus sp. nov., and $R$. (T.) foveaticeps sp. nov. from Atlantic rain forest are described and illustrated. A key for identification of the species of Atlantic Rain Forest are provided. Taxonomic notes on $R$. (C.) longifoveatus Azevedo, 1999, R. (C.) septemlineatus Kieffer, 1906, $R$. (C.) vesculus Evans, 1965, R. (C.) virescens Evans, $R$. (T.) cupreolus Evans, 1965, R. (T.) hirticulus Evans, 1965 and $R$. (T.) plaumanni Evans, 1965 are given and their geographic distribution recorded. The fauna of Rhabdepyris from the Atlantic Rain Forest is now represented by 25 species.
\end{abstract}

KEYWORDS. New species; parasitoid; Rhabdepyris; taxonomy.

\begin{abstract}
RESUMO. Dez espécies novas e notas sobre Rhabdepyris (Hymenoptera, Bethylidae) da Mata Atlântica. São descritas e ilustradas dez espécies novas de Rhabdepyris Kieffer, 1904: Rhabdepyris (Chlorepyris) atlanticus sp. nov., $R$. (C.) circinnatus sp. nov., $R$. (C.) clavatus sp. nov., $R$. (C.) ocultatus sp. nov., $R$. (C.) subangulatus sp. nov., $R$. (C.) sulcatus sp. nov., $R$. (C.) unifoveatus sp. nov., $R$. (R.) areolatus sp. nov., $R$. (Trichotepyris) curvicarinatus sp. nov., $R$. (T.) foveaticeps sp. nov.. É proposta uma chave para identificação para as espécies de Rhabdepyris da Mata Atlântica, e são apresentadas notas taxonômicas de $R$. (C.) longifoveatus Azevedo, 1999, $R$. (C.) septemlineatus Kieffer, 1906, $R$. (C.) vesculus Evans, 1965, R. (C.) virescens Evans, R. (T.) cupreolus Evans, 1965, R. (T) hirticulus Evans, 1965 e $R$. (T.) plaumanni Evans, 1965. Todas as espécies tiveram sua distribuição geográfica conhecida ampliada. A fauna de Rhabdepyris para a Mata Atlântica passa a ser representada por 25 espécies.
\end{abstract}

PALAVRAS-CHAVE. Espécies novas; parasitóides; Rhabdepyris; taxonomia.

O gênero Rhabdepyris Kieffer, 1904 possui 112 espécies válidas, 56 delas com ocorrência na região Neotropical, com 15 registros para a Mata Atlântica. Evans (1965) revisou o gênero para as Américas, separando-o nos subgêneros Trichotepyris Kieffer, 1906, Chlorepyris Kieffer, 1913 e Rhabdepyris sensu stricto. Ressaltou que cada um destes subgêneros apresentam tendências evolutivas associadas a outros gêneros distintos, tornando difícil estabelecer um delineamento preciso do gênero.

Este estudo teve como objetivo analisar taxonomicamente a fauna de Rhabdepyris da Mata Atlântica e incluir análise daquelas espécies claramente direcionadas a este gênero.

\section{MATERIAL E MÉTODOS}

O material examinado é proveniente das seguintes coleções, sob responsabilidade dos respectivos curadores: CASC California Academy of Science (R. Zuparko), DZUP - Coleção Pe. J. S. Moure da Universidade Federal do Paraná (K. Zanol), MCZH - Museum of Comparative Zoology, Harvard University (S. Cover), MPEG - Museu Paraense Emílio Goeldi (A. Harada), MZSP - Museu de Zoologia da Universidade de São Paulo (C.R.F. Brandão), UFES - Universidade Federal do Espírito Santo (C.O. Azevedo) e UFMG - Universidade Federal de
Minas Gerais (F. Silveira). A maior parte deste material é oriunda de coletas provenientes dos projetos "Riqueza de Hymenoptera e Isoptera ao longo de um gradiente latitudinal da Mata Atlântica" financiado pelo programa BIOTA/FAPESP "Biodiversidade da Mata Atlântica do Espírito Santo" e "Levantamento da Fauna Entomológica do ParanáPROFAUPAR", financiados pelo CNPq. Tais coletas foram realizadas ao longo de um gradiente latitudinal da Mata Atlântica, predominantemente em Floresta Ombrófila Densa. Entretanto, foi incorporado material disponível proveniente de outras formações vegetais da Mata Atlântica, como Floresta Estacional Semidecidual e Floresta Ombrófila Mista e Restinga. No total, foram estudados 229 exemplares, sendo 176 machos.

\section{TERMINOLOGIA E ABREVIAÇÕES}

Os termos de estruturas utilizados neste estudo segue Evans (1964). Foram adotados os seguintes índices e medidas: comprimento da cabeça (LH), em vista dorsal, desde a crista do vértice medianamente até a margem apical do clípeo; maior largura da cabeça (WH), usada na relação com LH para expressar o formato da cabeça; largura mínima da fronte (WF), no ponto mais próximo das órbitas internas dos olhos, usada na relação com WH para expressar amplitude; comprimento 
lateral máximo do olho (HE), usado na relação com WF para expressar o tamanho relativo dos olhos; distância ocelo-ocular (OOL), em vista látero-dorsal, a menor distância entre a órbita externa do ocelo posterior até a órbita interna do olho; largura máxima do triângulo ocelar (WOT), em vista dorsal, incluindo as laterais dos ocelos posteriores, usada na relação com OOL para expressar a compacidade do triângulo ocelar; diâmetro máximo do ocelo anterior (DAO), em vista dorsal, usado em relação com WOT para expressar o seu tamanho relativo e auxiliar na expressão da compacidade do triângulo ocelar; distância do triângulo ocelar ao vértice, em vista dorsoposterior, representando a distância máxima da margem posterior do olho até a crista do vértice, usada na relação com DAO para expressar a posição do triângulo ocelar na fronte; comprimento/largura do disco propodeal, para expressar seu comprimento relativo; comprimento/largura dos fêmures anteriores, para expressar a sua largura relativa; comprimento da asa anterior (LFW), do ponto de contato com a tégula até a parte mais distal da asa; comprimento do corpo (LB), em vista dorsal. Um termo, porém, necessita ser esclarecido, a carena adicional irregular corresponde a uma estria longitudinal forte que não conflui com a carena transversal anterior do disco propodeal. Os termos da textura do integumento como areolado, lineado e estrigulado segue Harris (1979).

As ilustrações representam os espécimes em posição de repouso, com o disco pronotal no mesmo plano do mesoscuto. Este procedimento é particularmente importante para a ilustração do mesossoma, pois alguns exemplares ao morrerem podem se curvar ventralmente, aumentando a área exposta do mesoscuto, dificultando a padronização da medida do mesoscuto e análise morfométrica das notáulices.

\section{RESULTADOS E DISCUSSÃO}

A fauna de Rhabdepyris conhecida para a Mata Atlântica era representada por: $R$. (C.) longifoveatus Azevedo, 1999; $R$. (C.) septemlineatus Kieffer, 1906; $R$. (C.) vesculus Evans, 1965; $R$. (C.) virescens Evans, 1965; R. (T.) cupreolus Evans, 1965; R. (T.) hirticulus Evans, 1965; R. (T.) plaumanni Evans, 1965; $R$. (C.) litoralis Azevedo, 1992; R. (C.) luteipennis Evans, 1965; R. (C.) muscarius (Westwood, 1874); R. (C.) puncticeps Evans, 1965; R. (C.) violaceus Evans, 1965; R. (R.) canchinensis Azevedo, 1992; R. (T.) fortunatus Evans, $1965 \mathrm{e}$ $R$. (T.) superpilosus Azevedo, 1993. Destas espécies, as sete primeiras foram novamente encontradas, enquanto todas as espécies citadas tiveram sua área de distribuição geográfica conhecida ampliadas. Foram encontradas ainda dez espécies descritas aqui como novas. A fauna de Rhabdepyris para a Mata Atlântica passa a ser representada por 25 espécies.

Síntese das espécies estudadas de Rhabdepyris da Mata Atlântica

Subgênero Chlorepyris

1. Rhabdepyris unifoveatus sp. nov., $0^{\pi}$, Brasil (ES)

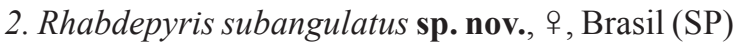

3. Rhabdepyris clavatus sp. nov., $0^{\pi}$, Brasil (MG)

4. Rhabdepyris ocultatus sp. nov., o ${ }^{\star}$, Brasil (PR)

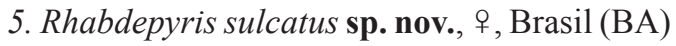

6. Rhabdepyris circinnatus sp. nov., $\sigma^{\star}$, Brasil (ES)

7. Rhabdepyris atlanticus sp. nov., o $\sigma^{\pi}$, Brasil (PR)

8. Rhabdepyris longifoveatus, Azevedo, 1999, o ${ }^{\star}$, Brasil (MG e SP)

9. Rhabdepyris septemlineatus Kieffer, 1906, ơ, Panamá, Nicarágua, Brasil (AM, MG, ES, RJ, SP, PR e SC)

10. Rhabdepyris vesculus Evans, 1965, ơ , Brasil (SE, MG, ES, RJ, SP e PR)

11. Rhabdepyris virescens Evans, 1965, ơ , + México, Panamá, Peru, Brasil (PB, BA, DF, MG, ES, SP, RJ, PR, $\mathrm{SC})$, Equador

Subgênero Rhabdepyris

12. Rhabdepyris areolatus sp. nov.,, , Brasil (MG)

Subgênero Trichotepyris

13. Rhabdepyris curvicarinatus sp. nov., , Brasil (MG)

14. Rhabdepyris foveaticeps sp. nov., $\sigma^{\top}$, Brasil (PR)

15. Rhabdepyris cupreolus Evans, 1965, ㅇ, Brasil (AL, $\mathrm{BA}, \mathrm{MG}$ e SC)

16. Rhabdepyris hirticulus Evans, 1965, ơ , + Panamá, Brasil (MG, ES, RJ, SP, PR e SC)

17. Rhabdepyris plaumanni Evans, 1965, o ${ }^{\star}$, 우, Brasil (PR, SC)

Chave para as espécies de Rhabdepyris da Mata Atlântica Machos

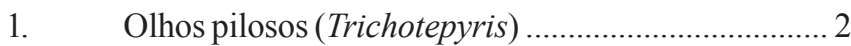

Olhos glabros (Chlorepyris) ........................................ 4

2(1). Fóveas margeando os olhos e na região mediana da fronte dispostas em fileira (Fig. 29)

R. (T.) foveaticeps sp.nov.

Fóveas, quando presente, não assumindo tal disposição .3

3(2). Corpo recoberto por pêlos grossos e escuros; disco propodeal com 5 carenas discais

R. (T.) hirticulus Evans, 1965

Corpo recoberto por pêlos finos e claros; disco propodeal com 7 carenas discais

.R. (T.) plaumanni Evans, 1965

4(1). Mesopleura com apenas uma fóvea (Fig. 2) R. (C.) unifoveatus sp. nov.

Mesopleura com duas fóveas, uma inferior e outra superior (Fig. 6) ………………………………….... 5

5(4). Fóvea inferior da mesopleura completamente fechada (Fig. 28) 6

Fóvea inferior da mesopleura pelo menos com a margem superior aberta (Fig. 6) 
6(5). Disco propodeal com 5 carenas discais R. (C.) luteipennis Evans, 1965

Disco propodeal com 5 carenas discais, mais 2 carenas adicionais irregulares (Fig. 21)

7(6). Genitália com cúspides escavadas em vista lateral, parâmeros largos, com as margens dorsal e ventral divergentes até a região mediana (Fig. 23)

$R$. (C.) atlanticus sp. nov.

Genitália com cúspide não escavada, parâmeros estreitos, com as margens dorsal e ventral praticamente paralelos até a região mediana R. (C.) septemlineatus Kieffer, 1906

8(5). Fóvea superior da mesopleura pequena, completamente fechada (Figs. 22, 28) .................... 9

Fóvea superior da mesopleura alongada, aberta posteriormente (Figs. 8,18 ) 10

9(8). Fronte e mesopleura, com pontuações pequenas e esparsas .........R. (C.) muscarius (Westwood, 1874)

Fronte e mesopleura com pontuações largas e abundantes ............ R. (C.) puncticeps Evans, 1965

10(8). Terceiro artículo antenal extremamente reduzido, com a face dorsal com forma triangular (Fig. 17) R. (C.) circinnatus sp. nov.

Terceiro artículo antenal, quando reduzido, não como acima .

11 (10). Cabeça e tórax azulado ou violeta; disco propodeal azulado R. (C.) violaceus Evans, 1965

Cabeça e tórax pretos ou com reflexos esverdeado; disco propodeal preto .. 12

12 (11). Disco propodeal com 3 carenas discais R. (C.) longifoveatus Azevedo, 1999 Disco propodeal com 5 carenas discais 13

13 (12). Genitália com parâmeros distintamente mais estreitos na base (Fig. 9) R. (C.) clavatus sp.nov. Genitália com parâmeros mais largos na base (Fig. 13) 14

14 (13). Genitália com cúspides seu ápice tão alto quanto o ápice dos parâmeros (Figs. 13, 14)

R. (C.) ocultatus sp. nov.

Genitália com cúspides seu ápice distintamente mais baixo do que ápice dos parâmeros ... 15

15 (14). Genitália com parâmeros muito largos, comprimento máximo cerca de 1,2 vezes maior do que a largura máxima, estreitamente pouco apicalmente .......... R. (C.) vesculus Evans, 1965

Genitália com parâmeros muito largos, comprimento máximo cerca de 2 vezes maior do que a largura máxima, estreitamente muito apicalmente

R. (C.) virescens Evans, 1965
Fêmeas

1. Olhos pilosos (Trichotepyris) ……………................ 2

Olhos glabros ……………………………………….... 7

2(1). Olhos densamente pilosos; asas anteriores com duas faixas escuras separadas por uma faixa clara próximo ao estigma ................................................................. 3

Olhos fracamente pilosos; asas anteriores com coloração uniforme

... 4

3(2). Disco propodeal com 5 carenas discais, mais 2 carenas adicionais irregulares; escrobo antenal não carenado .................. R. (T.) cupreolus Evans, 1965

Disco propodeal com 5 carenas discais, mais 4 carenas adicionais irregulares; escrobo antenal carenado .. R. (T.) superpilosus Azevedo, 1993

4(2). Corpo recoberto por pêlos grossos e escuros ........... ... R. (T.) hirticulus Evans, 1965

Corpo recoberto por pêlos finos e pálidos 5

5(4). Mesopleura com a fóvea inferior completamente fechada (Fig. 28) ...... R. (T.) curvicarinatus sp. nov.

Mesopleura com a fóvea inferior com a margem superior aberta

6(5). Corpo pequeno, LFW $2.2 \mathrm{~mm}$; disco propodeal completamente recoberto por estrias transversais R. (T.) plaumanni Evans, 1965

Corpo grande, LFW 2.4-3.0 mm; disco propodeal polido, no máximo com estrias fracas lateralmente R. (T.) fortunatus Evans, 1965

7(1). Corpo com pêlos escuros; disco pronotal com a margem posterior foveolada (Rhabdepyris) ........ 8

Corpo com pêlos pálidos; disco pronotal com a margem posterior não foveolada (Chlorepyris) .. 9

8(7). Disco propodeal com 5 carenas discais (Fig. 25) ....... $R$. (R.) areolatus sp. nov.

Disco propodeal com 9 carenas discais R. (R.) canchinensis Azevedo, 1992

9(7). Fóvea inferior da mesopleura completamente fechada .R. (C.) luteipennis Evans, 1965

Fóvea inferior da mesopleura pelo menos com a margem superior aberta 10

10(9). Cabeça desenvolvida na porção anterior, com as antenas inseridas bem abaixo do nível da margem inferior dos olhos ....

. .11

Cabeça curta anteriormente, com as antenas inseridas no mesmo nível ou quase da margem inferior dos olhos

11 (10). Cabeça e tórax pretos sem reflexos metálicos .R. (C.) muscarius (Westwood, 1874) 
Cabeça e tórax pretos com reflexos metálicos verdeoliva. R. (C.) virescens Evans, 1965

12 (10). Cabeça, tórax e disco propodeal azulado ou violeta ....... R. (C.) violaceus Evans, 1965

Disco propodeal preto, sem reflexos metálicos, contrastando com a cabeça e o tórax 13

13 (12). Cabeça com vértice subangulado medianamente; disco propodeal com carena mediana e segundo par completas (Fig. 5) .....R. (C.) subangulatus sp. nov.

Cabeça com vértice não como acima; disco propodeal com apenas a carena mediana completa (Fig. 15) ...

14

14(13). Mandíbula com um dente pré-apical na margem inferior R. (C.) litoralis Azevedo, 1992 Mandíbula sem dente pré-apical na margem inferior R. (C.) sulcatus sp. nov.

\section{Rhabdepyris (Chlorepyris) unifoveatus sp. nov. (Figs. 1-4)}

Descrição. Macho, holótipo: LB 5,32 mm; LFW 2,96 mm.

Cor. Corpo preto, cabeça, tórax e espaço lateral à carena paramediana do disco propodeal com reflexos verde-escuros metálicos; palpos, mandíbulas, antenas e tégulas castanhas; escapos pretos; pernas castanho-escuras, tíbias e tarsos castanhos; asas hialinas; nervuras e estigma castanhos.

Cabeça (Fig. 1). Mandíbulas com 5 dentes apicais, os 3 superiores pequenos e o inferior grande. Clípeo com o lobo mediano subangulado e pequeno, carena mediana evidente, formando uma reentrância na região de contato com a fronte. Escrobo antenal não carenado. Razão entre os 4 primeiros artículos antenais 18:11:4:16. Fronte coriácea, pontuações pequenas e conspícuas, separadas 2-3 vezes seus diâmetros, com uma sutura mediana fraca. WH 1,15 X LH; WF 0,68 X WH; WF 1,39 X HE; OOL 0,7 X WOT, distância dos ocelos posteriores à crista do vértice menor do que DAO. Vértice ligeiramente convexo, têmporas curtas e pouco divergentes.

Mesossoma (Fig. 1). Dorso do tórax coriáceo e pontuado; comprimento do disco pronotal 1,23 vezes mais longo do que mesoscuto; notáulices completas, distantes 2 vezes sua largura posterior; sulcos parapsidais sinuosos, incompletos anteriormente. Sulco escutelar profundo e muito fino, com as extremidades dilatadas e arredondadas. Disco propodeal 1,16 vezes mais largo do que longo, com 3 carenas discais, carena mediana completa, as demais incompletas, paramedianas convergindo posteriormente e tocando na mediana; região lateral do disco côncava, com uma fóvea 3,2 vezes mais longa do que larga, carena lateral mais inferior do que a carena sublateral em perfil, formando uma cavidade alongada e polida; disco estriado, estrias laterais às carenas discais mais fracas; cantos posteriores foveolados; declividade com carena mediana e estrias perpendiculares; lateral do propódeo fortemente lineada. Mesopleura com uma fóvea grande e alongada, aberta posteriormente, 2,71 vezes mais longa do que a largura mediana (Fig. 2). Tíbia mediana espinhosa. Fêmur anterior 2,42 vezes mais longo do que largo. Garras tarsais trífidas, dente basal arredondado e os demais pontiagudos.

Genitália (Fig. 3-4). Parâmero 0,45 vezes mais largo do que longo, ápice largo, margem dorsal côncava distalmente, margem ventral reta, praticamente paralela à dorsal e formando um pequeno dente entre a margem ventral e dorsal, base larga, obliqua e mais desenvolvida dorsalmente; volsela com cúspides dilatadas na base e inferiores aos parâmeros, dígitos muito mais curtos do que as cúspides; edeago mais baixo do que os dígitos, base dilatada e angulada abaixo, apódemas dilatados abaixo.

Material examinado. Holótipo: $0^{\pi}$; BRASIL, Espírito Santo, Linhares, Reserva Biológica de Sooretama, 22.III.2002, 1900'11.5" S $40^{\circ} 07^{\prime} 08^{\prime \prime}$ O, varredura, C. O. Azevedo \& eq. col. (MZSP).

Observações. Esta espécie apresenta o terceiro artículo antenal muito pequeno como em $R$. (C.) blantoni Evans, 1965, que possui reflexos azul-esverdeados, 5 carenas discais e duas fóveas na mesopleura, enquanto esta espécie possui reflexos verde-escuros metálicos, 3 carenas discais e apenas uma fóvea na mesopleura. O disco propodeal semelhante a $R$. (C.) longifoveatus, inclusive com a cavidade longitudinal, mas difere desta por apresentar o terceiro artículo antenal muito reduzido, reflexos verde-escuro metálicos e apenas 1 fóvea na mesopleura. As superfícies da mesopleura, metapleura e lateral do propódeo são planas. Conhecido apenas do holótipo.

Epíteto específico refere-se à presença de apenas uma fóvea na mesopleura.

\section{Rhabdepyris (Chlorepyris) subangulatus sp. nov.} (Figs. 5-6)

Descrição. Fêmea, holótipo: LB 6,4 mm; LFW 3 mm.

Cor. Corpo preto; cabeça, tórax, espaço lateral às carenas discais, escapo e pernas anteriores com reflexos azuis metálicos; palpos, mandíbulas, antenas e tégulas castanho-escuros; coxas pretas, trocanteres e fêmures castanho-escuros, tíbias e tarsos castanhos; asas anteriores subhialinas; nervuras e estigma castanhos.

Cabeça (Fig. 5). Mandíbulas com 1 dente pré-apical pontiagudo na margem inferior voltado para dentro e 5 dentes apicais, os 3 superiores pequenos e o inferior grande. Clípeo com lobo mediano subangulado, carena mediana evidente, formando uma reentrância na região de contato com a fronte. Escrobo antenal não carenado. Razão entre os 4 primeiros artículos antenais 16:7:7:9. Fronte coriácea, pontuações conspícuas, separadas 1-3 vezes seus diâmetros, com uma sutura mediana fraca. WH 1,01 X LH; WF 0,72 X WH; WF 1,44 X HE; OOL 1,12 X WOT, distância dos ocelos posteriores à crista do vértice 2,5 X DAO. Vértice convexo, subangulado medianamente, têmporas paralelas.

Mesossoma (Fig. 5). Dorso do tórax menos coriáceo do que a fronte; disco pronotal 1,61 vezes mais longo do que mesoscuto; notáulices largas, profundas e completas, 
distantes 2,5 vezes sua largura posterior; sulcos parapsidais pouco sinuosos e finos, incompletos anteriormente. Sulco escutelar profundo e fino, com as extremidades dilatadas e subcirculares. Disco propodeal 1,21 vezes mais largo do que longo, com 5 carenas discais, carenas mediana e segundo par completas, as paramedianas incompletas, divergindo um pouco posteriormente; carena lateral mais inferior do que a carena sublateral em perfil, formando uma cavidade alongada estriada, disco estriado entre as carenas discais; cantos posteriores foveolados; declividade com carena mediana, pontuações e estrias basais perpendiculares; lateral do propódeo lineado posteriormente. Mesopleura com fóvea superior fechada e alongada, 4,36 vezes mais longa do que a largura mediana, fóvea inferior grande, margem superior aberta anteriormente (Fig. 6). Tíbia mediana espinhosa. Fêmur anterior 2,12 vezes mais longo do que largo. Garras tarsais trífidas, dente basal angulado, mediano truncado e distal pontiagudo.

Material examinado. Holótipo: fêmea; BRASIL, São Paulo, Pariquera-açu, 24.VII.1986, Möricke, cultura de chá, sem dados do coletor (UFES). Parátipos: BRASIL, 12 ㅇ, mesmos dados do holótipo, exceto datas 20.III.1986 a 19.III.1987 (UFES).

Variação. Coloração dos reflexos violeta, azul e azulesverdeado.

Observações. Esta espécie chega em $R$. (C.) tricolor e $R$. (C.) violaceus na chave de Evans (1965), mas difere no padrão de coloração das pernas; em $R$. (C.) tricolor, as pernas são ferrugineas, exceto as coxas pretas e partes laterais dos fêmures anteriores; em $R$. (C.) violaceus, as pernas são escuras, fêmures anteriores e posteriores com reflexos azulados. Nesta espécie, as coxas são pretas, trocanteres e fêmures castanho-escuros, tíbias e tarsos castanhos. Difere ainda de $R$. (C.) violaceus por não apresentar as 5 carenas discais completas, mas apenas 3. A fronte de $R$. (C.) tricolor é fracamente coriácea, enquanto nesta espécie é coriácea.

Epíteto específico refere-se à forma do vértice.

\section{Rhabdepyris (Chlorepyris) clavatus sp. nov.}

(Figs. 7-10)

Descrição. Macho, holótipo: LB 4,52 mm; LFW 2,08 mm.

Cor. Corpo preto, cabeça e tórax com reflexos verde-escuros metálicos fracos; mandíbulas e antenas castanho-escuras; palpos e tégulas castanhas; pernas castanho-escuras com tíbias e tarsos castanhos; asas anteriores subhialinas; nervuras e estigma castanhos.

Cabeça (Fig. 7). Mandíbulas com 5 dentes apicais, os 3 superiores pequenos e o inferior grande. Clípeo com lobo mediano angulado, carena mediana evidente. Escrobo antenal não carenado. Razão entre os 4 primeiros artículos antenais 11:4:3:4. Fronte fracamente coriácea, quase polida, pontuações diminutas, separadas 2-4 vezes seus diâmetros. WH 1,09 X LH; WF 0,69 X WH; WF 1,34 X HE; OOL 0,81 X WOT, distância dos ocelos posteriores à crista do vértice menor do que DAO. Vértice ligeiramente arredondado, têmporas curtas e divergentes.
Mesossoma (Fig. 7). Dorso do tórax mais coriáceo do que a fronte; disco pronotal 1,54 vezes mais longo do que mesoscuto; notáulices completas, largas posteriormente, distantes 2 vezes sua largura posterior; sulcos parapsidais sinuosos e finos, incompletos anteriormente. Sulco escutelar profundo, largo com extremidades dilatadas e voltadas para trás. Disco propodeal 1,33 vezes mais largo do que longo, com 5 carenas discais, carena mediana completa, as demais incompletas, segundo par convergindo posteriormente; carena lateral mais inferior do que a carena sublateral em perfil, formando uma cavidade alongada com uma estria central da qual partem estrias perpendiculares; disco estriado entre as carenas discais, estrias laterais restritas às margens das carenas sub-laterais e segundo par; cantos posteriores foveolados; declividade com carena mediana, estrias transversais do ápice à base; lateral do propódeo lineado posteriormente. Mesopleura com fóvea superior alongada, aberta atrás e curva, fóvea inferior grande, margem superior aberta medianamente (Fig. 8). Tíbia mediana espinhosa. Fêmur anterior 2,22 vezes mais longo do que largo. Garras tarsais trífidas, dente basal arredondado, demais pontiagudos.

Genitália (Fig. 9-10). Parâmeros com ápice largo e reto, margem dorsal côncava medianamente e acima, com base fortemente convexa, margem ventral ligeiramente sinuosa com base convexa, base larga angulada dorsalmente; volsela com cúspides mais baixas do que os parâmeros e dilatadas abaixo, dígitos um pouco abaixo das cúspides; edeago tão alto quanto os dígitos, base dilatada e arredondada abaixo, apódemas dilatados abaixo.

Material examinado. Holótipo: $0^{\star}$; BRASIL, Minas Gerais, Belo Horizonte, Estação Ecológica, 5.XII.1996, armadilha Malaise, J.C.R. Fontenelle col. (UFMG).

Observações. Estruturas externas muito semelhantes a $R$. (C.) vesculus, contudo a genitália apresenta um padrão pouco comum em Rhabdepyris, os parâmeros próximo à base, fortemente convexos na região dorsal, enquanto $R$. (C.) vesculus apresenta essa região mais larga. É conhecido apenas a partir do holótipo.

Epíteto específico refere-se à forma do parâmero.

\section{Rhabdepyris (Chlorepyris) ocultatus sp. nov.}

(Figs. 11-14)

Descrição. Macho, holótipo: LB 5,48 mm; LFW 3,32 mm.

Cor. Corpo preto, cabeça, tórax e coxas com reflexos verdeescuros metálicos; palpos, antenas e tégulas castanhos; mandíbulas e escapos castanho-escuros; pernas castanhas; asas anteriores subhialinas; nervuras e estigma castanhos.

Cabeça (Fig. 11). Mandíbulas com 5 dentes apicais, os 3 superiores pequenos e o inferior grande. Clípeo com lobo mediano angulado, carena mediana evidente, formando uma reentrância na região de contato com a fronte. Escrobo antenal não carenado. Razão entre os 4 primeiros artículos antenais 17:6:6:10. Fronte quase polida, pontuações conspícuas, separadas $1-2$ vezes seus diâmetros, com uma sutura mediana 
fraca. WH 1,16 X LH; WF 0,69 X WH; WF 1,60 X HE; OOL 1,00 $\mathrm{X}$ WOT, distância dos ocelos posteriores à crista do vértice 1 $\mathrm{X}$ DAO. Vértice reto, têmporas curtas e divergentes.

Mesossoma (Fig. 11). Dorso do tórax polido; disco pronotal 1,36 vezes mais longo do que mesoscuto; notáulices completas e largas posteriormente, distantes 2 vezes sua largura posterior; sulcos parapsidais sinuosos e finos, incompletos anteriormente. Sulco escutelar profundo, com as extremidades elípticas. Disco propodeal 1,50 vezes mais largo do que longo, com 5 carenas discais, carena mediana completa, as demais incompletas, paramedianas paralelas e segundo par convergindo posteriormente quase tocando a mediana; região lateral do disco côncava, com uma fóvea 3 vezes mais longa do que larga, carena lateral mais inferior do que a carena sublateral em perfil, formando uma cavidade alongada não estriada; disco estriado entre as carenas discais; cantos posteriores foveolados; declividade com carena mediana, estrias basais fortes, coriácea com poucas pontuações; lateral do propódeo fracamente lineado. Mesopleura com fóvea superior aberta e alongada, arqueada posteriormente, fóvea inferior grande, margem superior aberta medianamente (Fig. 12). Tíbia mediana espinhosa. Fêmur anterior 1,95 vezes mais longo do que largo. Garras tarsais trífidas, dente basal angulado, mediano truncado e distal pontiagudo.

Genitália (Fig. 13-14). Parâmeros com ápice fino, margem dorsal côncava, margem ventral ligeiramente convexa, base larga, mais desenvolvida dorsalmente; volsela com cúspides tão altas quanto os parâmeros, dígitos muito mais curtos do que as cúspides; edeago tão alto quanto o dígito, base dilatada e arredondada abaixo, apódemas dilatados abaixo.

Material examinado. Holótipo: ơ; BRASIL, Paraná, Jundiaí do Sul, Faz. Monte Verde 11.I.1988, armadilha Malaise, Profaupar (DZUP). Parátipos: BRASIL, $3 \sigma^{\star}$, mesmos dados do tipo, exceto datas 18.I.1988, 4.II.1988 e 14.III.1988 (DZUP).

Observações. Esta espécie é semelhante a R. (C.) virescens, entretanto não possui dente pré-apical na mandíbula. A genitália de $R$. (C.) virescens apresenta parâmero com base larga e desenvolvida dorsalmente, cúspide mais baixa do que o parâmero e edeago mais alto do que o dígito, enquanto nesta espécie apresenta o parâmero com base arredondada na região dorsal e ligeiramente escavado na região mediana, cúspide tão alta quanto o parâmero, edeago tão alto quanto o dígito.

Epíteto específico refere-se ao fato da fronte projetar-se sobre o clípeo.

\section{Rhabdepyris (Chlorepyris) sulcatus sp. nov.}

(Figs. 15-16)

Descrição. Fêmea, holótipo: LB 4,64 mm; LFW 2,68 mm.

Cor. Corpo preto; cabeça e tórax com reflexos verde-oliva, mandíbulas, antenas e tégulas castanhos; palpos castanhoclaros; pernas castanhas, exceto todas as coxas e fêmures posteriores castanho-escuros; asas anteriores subhialinas; nervuras e estigma castanhos.

Cabeça (Fig. 15). Mandíbulas com 5 dentes apicais, os 3
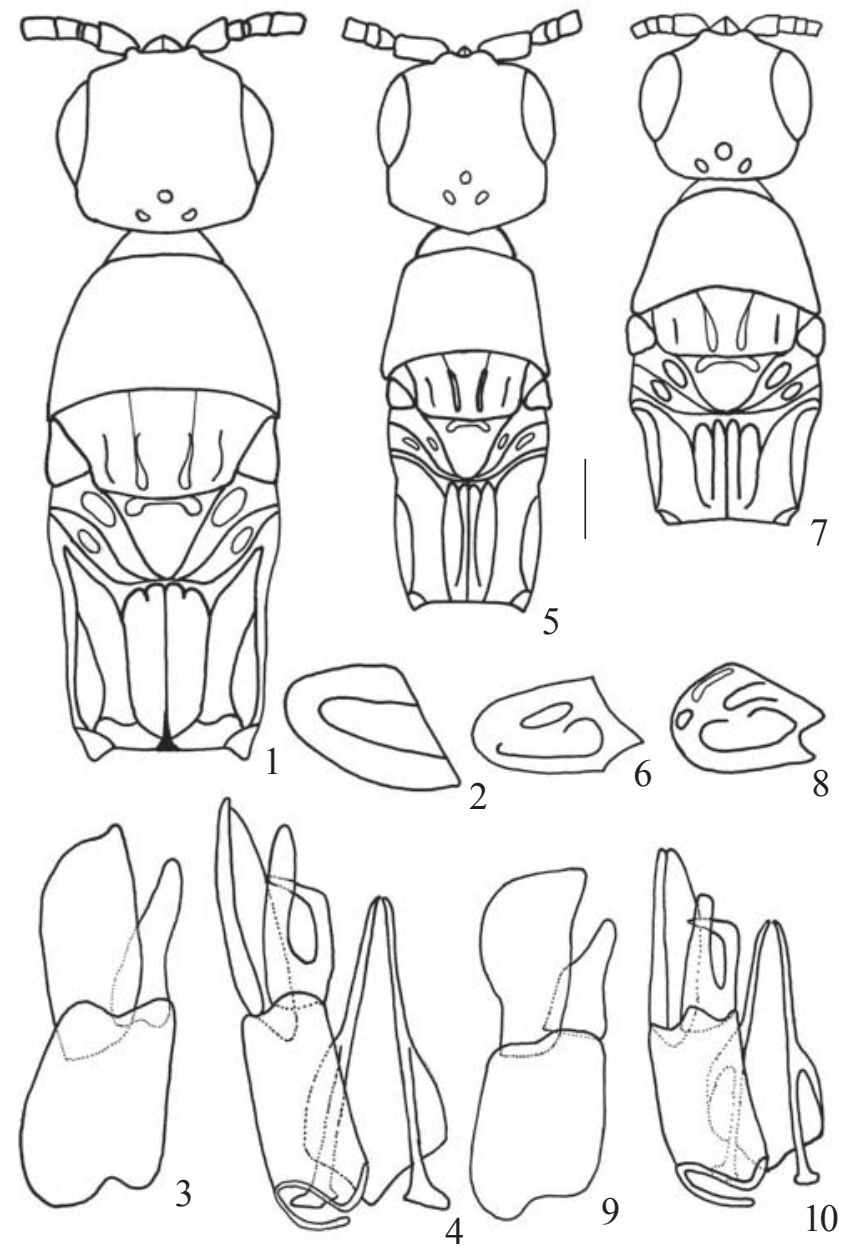

Figs. 1-10. 1-4, Rhabdepyris unifoveatus: 1, holótipo macho, cabeça e Mesossoma, dorsal; 2, mesopleura, lateral; 3, genitália, lateral; 4, genitália, ventral; 5-6, Rhabdepyris subangulatus: 5, holótipo fêmea, cabeça e Mesossoma, dorsal; 6, mesopleura, lateral; 7-10, Rhabdepyris clavatus: 7, holótipo macho, cabeça e Mesossoma, dorsal; 8, mesopleura, lateral; 9, genitália, lateral; 10, genitália, ventral. (Escala, figs. 1, 2, 7 e $8=0,5 \mathrm{~mm}$; figs. 5 e $6=0,25 \mathrm{~mm}$; figs. $3,4,9$ e $10=155 \mu \mathrm{m})$.

superiores pequenos e o inferior grande. Clípeo com lobo mediano arredondado, carena mediana evidente, formando uma reentrância na região de contato com a fronte. Escrobo antenal não carenado. Razão entre os 4 primeiros artículos antenais 18:8:5:7. Fronte coriácea, com pontuações pequenas, separadas 1-3 vezes seus diâmetros, com uma sutura mediana. WH 1,00 X LH; WF 0,63 X WH; WF 1,07 X HE; OOL 1,11 X WOT, distância dos ocelos posteriores à crista do vértice 1,00 $\mathrm{X}$ DAO. Vértice reto, têmporas curtas e divergentes.

Mesossoma (Fig. 15). Dorso do tórax coriáceo, com pontuações; comprimento do disco pronotal 1,4 vezes mais longo do que mesoscuto; notáulices completas e largas posteriormente, distantes 2 vezes sua largura posterior; sulcos parapsidais sinuosos, incompletos anteriormente. Sulco escutelar profundo e fino, com as extremidades dilatadas e arredondadas. Disco propodeal 1,50 vezes mais largo do que 
longo, com 5 carenas discais, carena mediana completa, as demais incompletas, as paramedianas convergindo gradualmente e o segundo par convergindo posteriormente; carena lateral mais inferior do que a carena sub lateral em perfil, formando uma cavidade alongada estriada; disco estriado entre as carenas discais, estrias laterais às carenas discais fortes posteriormente; cantos posteriores foveolados; declividade com carena mediana, estrias basais fortes; lateral do propódeo fracamente lineada. Mesopleura com sulco estriado posteriormente, fóvea superior fechada, fóvea inferior grande, margem superior aberta medianamente (Fig. 16). Tíbia mediana espinhosa. Fêmur anterior 2,21 vezes mais longo do que largo. Garras tarsais trífidas, dente basal angulado, mediano truncado e distal pontiagudo.

Material examinado. Holótipo: fêmea; BRASIL, Bahia, Porto Seguro, Estação Ecológica Pau Brasil, 20.V.2002, 16²3'17.5"S $39^{\circ} 10^{\prime} 10,55^{\prime \prime} \mathrm{O}$, armadilha Malaise, C.O. Azevedo \& eq. col. (MZSP).

Observações. Esta espécie é semelhante a $R$. (C.) virescens, que possui um pequeno dente mandibular pré-apical, mesopleura sem um sulco posterior estriado, enquanto $R$. (C.) sulcatus não possui dente pré-apical e a mesopleura tem um sulco posterior estriado com início próximo à coxa mediana, estendendo até a tégula, com um septo próximo à fóvea superior. Conhecido apenas a partir do holótipo.

Epíteto específico refere-se à presença de um sulco estriado na mesopleura.

\section{Rhabdepyris (Chlorepyris) circinnatus sp. nov.} (Figs. 17-20)

Descrição. Macho, holótipo: LB 4,12 mm; LFW 2,2 mm.

Cor. Corpo preto, cabeça e tórax com reflexos verde-escuros metálicos fracos; escapos e tégulas castanho-escuro; mandíbulas, antenas e palpos castanhos; pernas castanhoescuras, com tíbias e tarsos castanho-claros; asas anteriores subhialinas; nervuras e estigma castanhos.

Cabeça (Fig 17). Mandíbulas com 5 dentes apicais, o inferior grande. Clípeo com lobo mediano angulado e grande, carena mediana evidente, formando uma reentrância na região de contato com a fronte. Escrobo antenal não carenado. Razão entre os 4 primeiros artículos antenais 17:5:2:18. Fronte fracamente coriácea, com pontuações diminutas, separadas 24 vezes seus diâmetros. WH 1,15 X LH; WF 0,69 X WH; WF 1,38 X HE; OOL 1,05 X WOT, distância dos ocelos posteriores à crista do vértice menor do que DAO. Vértice reto, têmporas divergentes.

Mesossoma (Fig. 17). Dorso do tórax coriáceo com pontuações; disco pronotal 1,58 vezes mais longo do que mesoscuto; notáulices completas, largas posteriormente, distantes 1,00 vez sua largura posterior; sulcos parapsidais sinuosos e finos, incompletos anteriormente. Sulco escutelar profundo, largo com extremidades arredondadas. Disco propodeal 1,28 vezes mais largo do que longo, com 5 carenas discais, carena mediana completa, as demais incompletas, segundo par convergindo posteriormente e tocando a mediana; região lateral do disco côncava com uma fóvea 3,9 vezes mais longa do que larga, carena lateral mais inferior do que a carena sublateral em perfil, formando uma cavidade alongada não estriada; disco estriado entre as carenas discais; cantos posteriores foveolados; declividade com carena mediana e estrias inferiores perpendiculares; lateral do propódeo lineada. Mesopleura com fóvea superior grande e aberta, 2,71 vezes mais longa do que a largura mediana, fóvea inferior com a margem superior amplamente aberta (Fig. 18). Tíbia mediana espinhosa. Fêmur anterior 2 vezes mais longo do que largo. Garras tarsais trífidas, dente basal arredondado, mediano truncado e distal pontiagudo.

Genitália (Fig. 19-20). Parâmeros com ápice arredondado, margem dorsal côncava medianamente até o ápice e margeada por pêlos, ligeiramente convexa na base, margem ventral sem os pêlos na região mediana, base triangular; volsela com cúspides tão altas quanto os parâmeros, dígitos muito mais curtos do que as cúspides; edeago mais alto do que os dígitos, base dilatada e angulada, apódemas dilatados abaixo.

Material examinado. Holótipo: $0^{\pi}$; BRASIL, Espírito Santo, Linhares, Reserva Biológica de Sooretama, 24-27.III.2002, $19^{\circ} 00^{\prime} 11.5^{\prime \prime S} 40^{\circ} 07^{\prime} 08^{\prime \prime} \mathrm{O}$, armadilha Malaise, C.O. Azevedo \& eq. col. (MZSP).

Observações. Esta espécie possui o terceiro artículo antenal extremamente pequeno, ventralmente muito menor do que dorsalmente, frontalmente em forma de triângulo. É semelhante a $R$.(C.) blantoni, porém difere deste por ter cabeça com reflexos esverdeados, terceiro segmento anelar, parâmeros com a base mais estreita do que o ápice e cúspides tão altas quanto os parâmeros, enquanto $R$. (C.) blantoni tem cabeça com reflexos azulados, terceiro segmento não anelado, ápice dos parâmeros mais estreito do que a base e cúspides mais baixas do que os parâmeros. É conhecido apenas a partir do holótipo.

Epíteto específico refere-se a forma de anel do terceiro artículo antenal.

\section{Rhabdepyris (Chlorepyris) atlanticus sp. nov.} (Figs. 21-24)

Descrição. Macho, holótipo: LB 6,56 mm; LFW 3,6 mm.

Cor. Corpo preto; palpos, mandíbulas, antenas, e tégulas castanhas; coxas pretas, trocanteres, fêmures, tíbias e tarsos castanhos, as posteriores castanho-escuras; asas anteriores amareladas; nervuras e estigma castanhos.

Cabeça (Fig. 21). Mandíbulas com 5 dentes apicais, os 4 superiores pequenos e arredondados, o inferior grande e pontiagudo. Clípeo com lobo mediano subangulado, carena mediana evidente. Escrobo antenal não carenado. Razão entre os 4 primeiros artículos antenais 17:4:15:15. Fronte polida, com pontuações diminutas, separadas 1-2 vezes seus diâmetros, com uma sutura mediana fraca. WH 0,96 X LH; WF 0,59 X WH; WF 1,17 X HE; OOL 1,45 X WOT, distância dos ocelos posteriores à crista do vértice menor do que DAO. Vértice reto, têmporas paralelas. 
Mesossoma (Fig. 21). Dorso do tórax quase polido, com pontuações diminutas; disco pronotal 1,33 vezes mais longo do que mesoscuto; notáulices completas, largas, pouco profundas e subparalelas, distantes 6 vezes sua largura posterior; sulcos parapsidais retos e largos, incompletos anteriormente. Sulco escutelar profundo e largo com extremidades não dilatadas, voltadas para trás. Disco propodeal 1,63 vezes mais largo do que longo, com 5 carenas discais, carena mediana completa, as demais incompletas, as paramedianas paralelas e quase completas, com um par de carenas adicionais irregulares acompanhando a mediana, segundo par convergindo posteriormente; carena lateral mais inferior do que a carena sublateral em perfil, formando uma cavidade alongado estriada; disco polido lateralmente às carenas discais; cantos posteriores foveolados; declividade com carena mediana e polida; lateral do propódeo lineada. Mesopleura com fóvea superior fechada e oval, fóvea inferior fechada, estreitando na região mediana (Fig. 22). Tíbia mediana espinhosa. Fêmur anterior 2,11 vezes mais longo do que largo. Garras tarsais trífidas, dente basal arredondado, mediano truncado e posterior pontiagudo.

Genitália (Fig. 23-24). Parâmeros largos com ápice pequeno, margem dorsal côncava, margem ventral ligeiramente convexa, mais nítida na base, base fortemente obliqua e pontiaguda dorsalmente; volsela com cúspides mais baixas do que os parâmeros e escavadas dorsalmente, dígitos mais curtos do que as cúspides; edeago mais alto do que as cúspides, base dilatada e angulada, apódemas dilatados abaixo.

Material examinado. Holótipo: ơ; BRASIL, Paraná, Jundiaí do Sul, Fazenda Monte Verde 22.XII.1986, armadilha Malaise, Profaupar (DZUP). Parátipos: BRASIL, 9 o $o^{x}$ dados idem ao tipo, exceto datas 11.VIII.1986-16.V.1987 (DZUP); Telêmaco Borba, 1 ơ , Reserva Samuel Klabin, 10.XI.1986, armadilha Malaise, Profaupar (DZUP).

Variação. Cúspide um pouco menos escavada do que a do tipo.

Observações. Espécie próxima à R. (C.) lobatifrons Kieffer, 1910, com caracteres externos muito semelhante e genitália também com a cúspide escavada. Entretanto difere desta por apresentar parâmero nitidamente mais largo nas regiões apicais e medianas.

Epíteto específico é uma alusão ao bioma Mata Atlântica.

\section{Rhabdepyris (Chlorepyris) longifoveatus Azevedo, 1999}

Esta espécie era conhecida para o Brasil (São Paulo) e agora é citada pela primeira vez para Minas Gerais e para o Espírito Santo.

Material examinado. BRASIL, Minas Gerais, 5 o $^{x}$, Belo Horizonte, Estação Ecológica, 31.V.1996 a 2.XII.1996, armadilha Malaise, J.C.R. Fontenelle col. (UFMG, UFES); $10^{x}$, Belo Horizonte, Prefeitura, 2.XII.1996, armadilha Malaise, J.C.R. Fontenelle col. (UFMG); Espírito Santo, $10^{\pi}$, Linhares, Fazenda Bom Conselho, 1-3.X.2000, varredura, Azevedo \& Schiffler col (UFES).
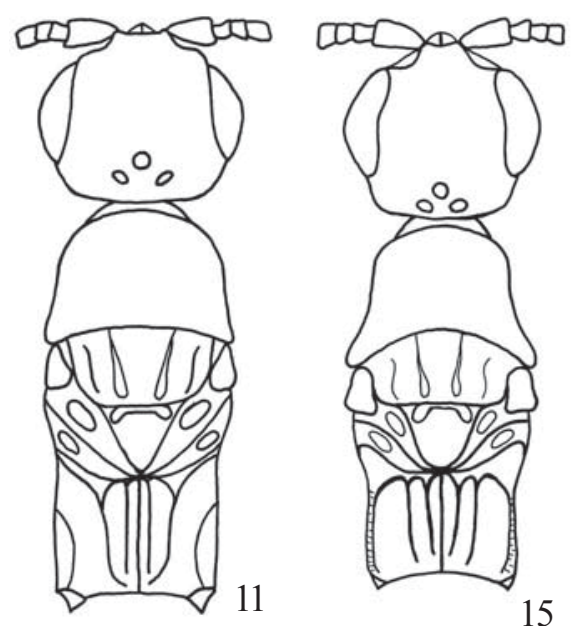

15
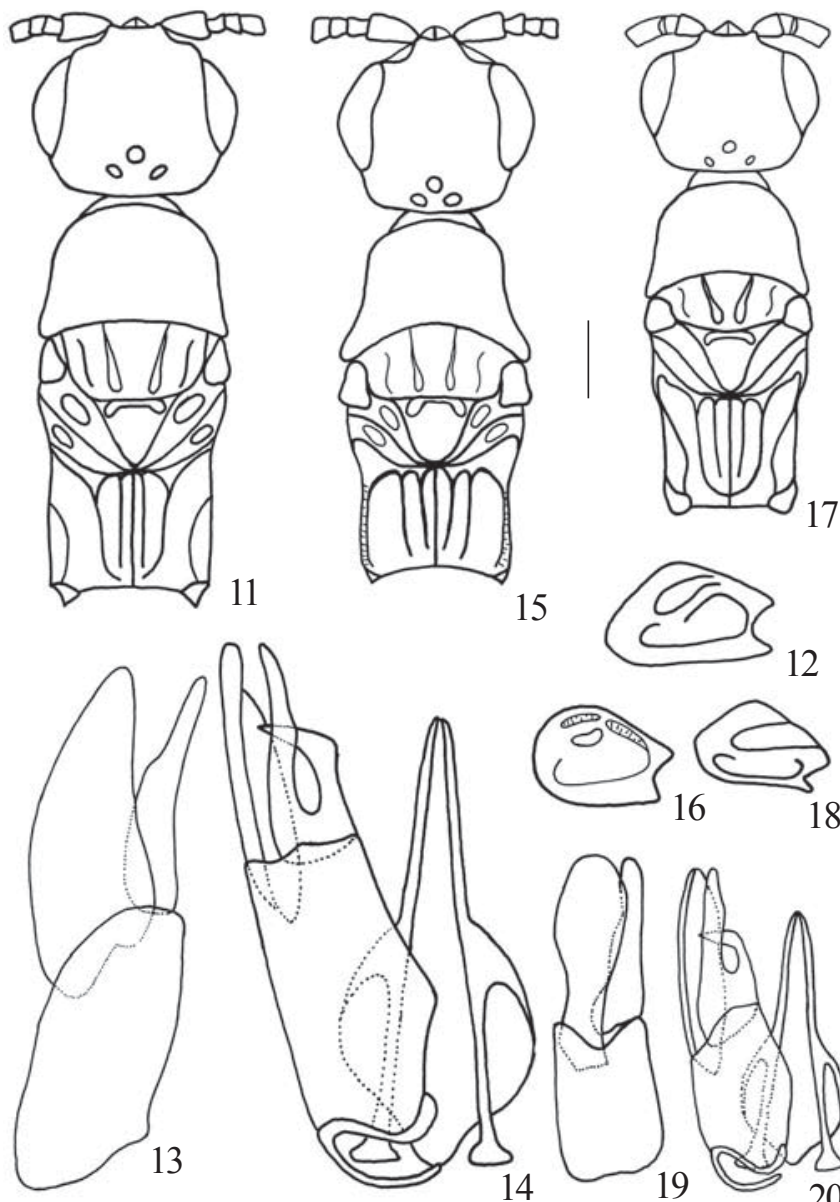

17

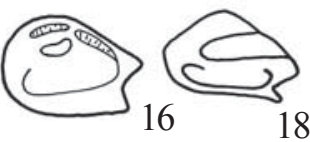

Figs. 11-20. 11-14, Rhabdepyris ocultatus: 11, holótipo macho, cabeça e Mesossoma, dorsal; 12, mesopleura, lateral; 13, genitália, lateral; 14, genitália, ventral; 15-16, Rhabdepyris sulcatus: 15, holótipo fêmea, cabeça e Mesossoma, dorsal; 16, mesopleura, lateral; 17-20, Rhabdepyris circinnatus: 17, holótipo, macho, cabeça e Mesossoma, dorsal; 18, mesopleura, lateral; 19, genitália, lateral; 20, genitália, ventral. (Escala figs. $11,12=0,25 \mathrm{~mm}$; figs. $15,16,17$ e $18=0,5 \mathrm{~mm} ; 13,14,19$ e 20 $=155 \mu \mathrm{m})$.

\section{Rhabdepyris (Chlorepyris) septemlineatus Kieffer, 1906}

Esta espécie era conhecida para o Panamá, Nicarágua e Brasil (Amazonas, Espírito Santo, São Paulo, Santa Catarina e Paraná) e agora foram encontrados pela primeira vez em Minas Gerais e Rio de Janeiro.

Observação. Nesta série, o parâmero apresenta margem ventral mais pontiaguda do que na série estudada por Azevedo (1999).

Material examinado. BRASIL, Minas Gerais, $4 \sigma^{*}$, Belo Horizonte, Estação Ecológica, 7.II.1996 a 28.XI.1996, armadilha Malaise, J.C.R. Fontenelle col. (UFMG); Espirito Santo, 1 o $^{*}$, Linhares, Fazenda Beneofort, Povoação, Restinga arbórea, 8-10.X.2000, varredura, Azevedo \& Schiffer col. (UFES); $4 \sigma^{\pi}$, Santa Teresa, Estação Biológica Santa Lúcia 638m, 07.IV.2001, 1958'2" S 40³1'6" O, varredura, C.O. Azevedo col. (MZSP); $1 \sigma^{\pi}$, Santa Teresa, 642m, 08.IV.2001, $19^{\circ} 58^{\prime} 29,4^{\prime \prime} \mathrm{S} 40^{\circ} 32^{\prime} 44,5^{\prime \prime}$ O, varredura, C.O. Azevedo col. (MZSP); 1 $\sigma^{\star}$, Santa Teresa, 867m, 9-12.IV.2001, armadilha Malaise, C.O. Azevedo 
\& eq. col. (MZSP); $3 \sigma^{\pi}$, Santa Teresa, 10.XII.2001, varredura, C.O. Azevedo \& Kawada col. (UFES); Vitória, Parque Estadual Fonte Grande, $2 \sigma^{*}, 15$.VIII.2000, Azevedo, Kawada \& Santos col. (UFES) e 11.VIII.2000, C.O. Azevedo \& Kawada col. (UFES); $3 \sigma^{x}$, Santa Maria de Jetibá, Fazenda Paulo Seick, 29.XI.-13.XII.2002, 2002’31,3" S $40^{\circ} 41$ '51,3" O, armadilha Malaise, M.T. Tavares, C.O. Azevedo \& eq .col. (UFES); $20^{x}$, Santa Maria de Jetibá, Fazenda Clarindo Krueger, 29.XI-06XII.2002, 2004'27,9" S 4044'51,3" O, armadilha Malaise, M.T. Tavares, C.O. Azevedo \& eq .col. (UFES); Rio de Janeiro, $1 \sigma^{\pi}$, Santa Maria Madalena, Parque Estadual Desengano, 16-19.IV.2002, $21^{\circ} 59^{\prime} 03^{\prime \prime} \mathrm{S} 41^{\circ} 57^{\prime} 08^{\prime \prime} \mathrm{O}$, armadilha Malaise, A.M. Penetado-Dias \& eq. col. (MZSP); $5 \sigma^{x}$, Nova Iguaçu, Reserva Biológica do Tingua, 58.III.2002, $22^{\circ} 34^{\prime} 28^{\prime \prime} \mathrm{S} 43^{\circ} 26^{\prime} 09^{\prime \prime} \mathrm{O}$, armadilha Malaise S.T.P. Amarante \& eq. col. (MZSP); São Paulo, $10^{x}$, Peruíbe, E. E. Juréia-

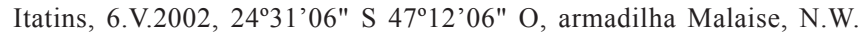
Perioto \& eq. col. (MZSP); $1 \sigma^{x}$, Ribeirão Grande, Parque Estadual Intervales, 10-13.XII.2002, armadilha Malaise, M.T. Tavares \& eq. col. (MZSP); Paraná, $510^{\pi}$, Jundiaí do Sul, Fazenda Monte Verde, 1.IV30.XI.1987, armadilha Malaise, Profaupar (DZUP).

\section{Rhabdepyris (Chlorepyris) vesculus Evans, 1965}

Esta espécie era conhecida para o Brasil (Espírito Santo, São Paulo e Paraná) e aqui é citada pela primeira vez para Sergipe e Minas Gerais. O exemplar coletado em Sergipe, Santa Maria de Itanhy, Crasto, trilha 5, apresenta parâmero lateralmente com um aspecto mais retangular do que o restante da série que possui o parâmero com ápice dorsal curvo, margem ventral ligeiramente escavada e base desenvolvida dorsalmente.

Material examinado. BRASIL, Sergipe, $2 \sigma^{\pi}$, Santa Maria do Itanhy, Crasto, 01-04.VIII.2001, $11^{\circ} 22^{\prime} 37,5^{\prime \prime} \mathrm{S} 37^{\circ} 24^{\prime} 50,3^{\prime \prime} \mathrm{O}$, armadilha Malaise, trilha 1 e trilha 5, M.T. Tavares \& eq .col. (MZSP); Minas Gerais, $1 \sigma^{\star}$, Belo Horizonte, Prefeitura, 28.XI.1996, armadilha Malaise, J.C.R. Fontenelle col. (UFMG); Espírito Santo, $20^{x}$, Linhares, Reserva Biológica Sooretama, 24-27.III.2002, 1900’11.5" S 4007’08" O, armadilha Malaise, C.O. Azevedo \& eq. col. (MZSP); $10^{x}$, Linhares, Fazenda Beneofort, Povoação, Restinga arbórea, 1-3.XI.2000, varredura, Azevedo \& Schiffer col. (UFES); Santa Teresa, Estação Biológica Santa Lúcia 638m, 4 ơ , 6-18.IV.2001, 1958'2" S 40³1'6" O, armadilha Malaise e $1 \sigma^{\pi}$, 07.IV.2001, varredura, C.O. Azevedo \& eq. col. (MZSP); $70^{x}$, Santa Teresa, Estação Biológica Santa Lúcia, 30.I.2001 a 28.III.2001, varredura, Azevedo \& Kawada col. (UFES) e $10^{x}$, Correa \& Santos col. (UFES); $10^{x}$, Santa Teresa, Estação Biológica Santa Lúcia 840m, 09-12.IV.2001, armadilha Malaise, C.O. Azevedo \& eq. col. (MZSP); 4 ơ, Vitória, Parque Estadual Fonte Grande, 4.I19.IV.2001, varredura, Azevedo \& Kawada col. (UFES); 3 o , Santa Maria de Jetibá, Fazenda Clarindo Krueger, 29.XI-06XII.2002, 200' $27,9^{\prime \prime} \mathrm{S} 40^{\circ} 44^{\prime} 51,3^{\prime \prime} \mathrm{O}$, armadilha Malaise, M.T. Tavares, C.O. Azevedo \& eq .col. (UFES); $30^{x}$, Santa Maria de Jetibá, Fazenda Paulo Seick, 29.XI-06XII.2002, 2002'31,3" S 4041'51,3" O, armadilha Malaise, M.T. Tavares, C.O. Azevedo \& eq .col. (UFES); Rio de Janeiro, Nova Iguaçu, Reserva Biológica do Tingua, $7 \sigma^{x}$, 5-11.III.2002, armadilha Malaise e $1 \sigma^{*}$, 7.III.2002, varredura, $22^{\circ} 34^{\prime} 28^{\prime \prime}$ S $43^{\circ} 26^{\prime} 09^{\prime \prime O}$, S.T.P. Amarante \& eq. col. (MZSP); São Paulo, 4 ơ , Ribeirão Grande, Parque Estadual Intervales, 10-13.XII.2002, armadilha Malaise, M.T. Tavares \& eq. col. (MZSP); Paraná, 8 ơ , Jundiaí do Sul, Fazenda Monte Verde, 16.III.1987-25.I.1988, armadilha Malaise, Profaupar (DZUP). Este material foi comparado como o holótipo macho do Brasil, Santa Catarina, Nova Teutônia (MCZH).

\section{Rhabdepyris (Chlorepyris) virescens Evans, 1965}

Esta espécie era conhecida para o México, Panamá, Brasil (Distrito Federal e nos Estados do Paraná, São Paulo e Santa
Catarina), Equador e Peru. É aqui citada pela primeira vez para Paraíba, Bahia, Minas Gerais, Espírito Santo e Rio de Janeiro. Das espécies que ocorrem na Mata Atlântica, esta é a que apresenta a maior distribuição geográfica. Neste estudo, esta foi a espécie que apresentou o maior acréscimo na distribuição geográfica com a primeira citação para cinco estados, passando a possuir também a maior distribuição no país, sendo citada agora para oito estados mais o Distrito Federal. Evans (1965) mencionou que esta espécie apresenta cinco carenas discais, mas não mencionou o formato das mesmas. Carena mediana é completa, paramediana paralela e quase completa, em alguns casos as estrias se fundem com a paramediana dando a impressão da mesma ser completa e segundo par paralelo e ligeiramente menor do que as paramedianas, ocupando cerca dos três quartos anteriores do disco.

Material examinado. BRASIL, Paraíba, 1, João Pessoa, Reserva do Buraquinho-IBDF, 29.I.1989, J. Dias col. (MPEG); Bahia, 1 우, Sapiranga, Reserva do Sapiranga, 19-22.VII.2001, 12³3'38.5" S $38^{\circ} 02^{\prime} 57,2^{\prime \prime} \mathrm{O}$, armadilha Malaise, M.T. Tavares \& eq. col. (MZSP); Minas Gerais, 1 ㅇ, Belo Horizonte,Estação Ecológica, 3.XII.1996, armadilha Malaise, J.C.R. Fontenelle col. (UFMG); 2 +, Belo Horizonte, Prefeitura, 2.XII.1996, armadilha Malaise, J.C.R. Fontenelle col. (UFMG); Espírito Santo, 1 오, Linhares, Reserva Biológica Sooretama, 24-27.III.2002, 1900’11.5" S 4007’08" O, armadilha Malaise, C.O. Azevedo \& eq. col.(MZSP); 1 + , Santa Teresa, Estação Biológica Santa Lúcia 638m, 6-9.IV.2001, 1958'2" S 40³1'6" O, armadilha Malaise, C.O. Azevedo \& eq. col. (MZSP); Rio de Janeiro, 1 \%, Santa Maria Madalena, Parque Estadual Desengano, 16-19.IV.2002, 21 $1^{\circ} 59^{\prime} 03^{\prime \prime} \mathrm{S}$ $41^{\circ} 57^{\prime} 08^{\prime \prime}$ O, armadilha Malaise, A.M. Penetado-Dias \& eq. col. (MZSP); Paraná, 1 \&, Jundiaí do Sul, Fazenda Monte Verde, 06.IV.1988, armadilha Malaise, Profaupar (DZUP); Santa Catarina, 1 \%, São Francisco do Sul, CEPA Vila da Glória, 14-17.X.2001, 26¹'40"S 4840’49"O, armadilha Malaise, Penteado-Dias \& eq. col. (MZSP). Este material foi comparado com o holótipo fêmea e o alótipo macho do Brasil, Santa Catarina, Nova Teutônia (MCZH).

\section{Rhabdepyris (Rhabdepyris) areolatus sp. nov.} (Figs. 25-26)

Descrição. Fêmea, holótipo: LB 2,2 mm; LFW 1,06 mm.

Cor. Corpo preto; mandíbulas, palpos, antenas, tégulas e pernas castanhas; exceto todas as coxas e fêmures anteriores castanho-escuros; asas anteriores hialinas; nervuras e estigma castanho-claros.

Cabeça (Fig. 25). Mandíbulas com 5 dentes apicais, os 3 superiores pequenos e o inferior grande e pontiagudo. Clípeo com lobo mediano arredondado e 1 dente anteriormente, carena mediana alta e angulada vista em perfil. Escrobo antenal não carenado. Razão entre os 4 primeiros artículos antenais 16:9:5:7. Fronte coriácea, pontuações pequenas e muito esparsas. WH 0,87 X LH; WF 0,73 X WH; WF 1,71 X HE; OOL 1,25 X WOT, distância dos ocelos posteriores à crista do vértice menor do que DAO. Vértice reto, têmporas divergentes.

Mesossoma (Fig. 25). Dorso do tórax coriáceo como a fronte; disco pronotal 1,37 vezes mais longo do que mesoscuto, com uma fileira de fóveas alongadas na margem posterior; notáulices ausentes; sulcos parapsidais incompletos anteriormente. Sulco escutelar profundo e largo com extremidades dilatadas. Disco propodeal 1,03 vezes mais largo 
do que longo, com 5 carenas discais, carenas mediana e paramedianas completas, segundo par terminando antes da porção mediana do disco; carena lateral e sublateral quase no mesmo plano em perfil; disco areolado entre as carenas discais, estrigulado lateralmente; cantos posteriores foveolados; declividade e lateral do propódeo areolados, carena mediana da declividade muito fraca. Mesopleura com fóvea superior fechada, pequena e arredondada, fóvea inferior não definida (Fig. 26). Tíbias medianas e posteriores com cerdas. Fêmur anterior 2,84 vezes mais longo do que largo.

Material examinado. Holótipo: fêmea; BRASIL, Minas Gerais: Belo Horizonte, 22.II.1998, D. Yanega (UFMG)

Observações. Esta espécie apresenta um padrão único dentro do subgênero Rhabdepyris, com apenas 5 carenas discais, 3 completas e as do segundo par reduzidas. O número de carenas discais no subgênero Rhabdepyris pode variar de 9 a 5 . As espécies com 5 carenas discais possuem no mínimo 2 carenas adicionais falsas. Outras diferenças marcantes são a ausência de notáulices, propódeo areolado e com poucas carenas discais. É conhecida apenas a partir do holótipo.

Epíteto específico refere-se a região entre as carenas discais areolada, o que é incomum.

\section{Rhabdepyris (Trichotepyris) curvicarinatus sp. nov.} (Figs. 27-28)

Descrição. Fêmea, holótipo: LB 3,76 mm; LFW 2,08 mm.

Cor. Cabeça e Mesossoma pretos, metassoma castanhoescuro; mandíbulas castanho-escuras; palpos e antenas castanhas; tégula castanho-clara; pernas castanho-escuras com tíbias e tarsos castanhos; asas anteriores subhialinas; nervuras e estigma castanho-claros.

Cabeça (Fig. 27). Mandíbulas com 5 dentes apicais, os superiores pequenos e arredondados, o inferior grande e pontiagudo. Clípeo com lobo mediano subangulado e grande, carena mediana evidente. Escrobo antenal não carenado. Razão entre os 4 primeiros artículos antenais 16:7:4:6. Fronte fracamente coriácea, pontuações conspícuas separadas 1-3 vezes seus diâmetros, com uma sutura mediana forte. WH 0,96 X LH; WF 0,62 X WH; WF 0,97 X HE; OOL 1,28 X WOT, distância dos ocelos posteriores à crista do vértice menor do que DAO. Vértice fracamente convexo, têmporas divergentes.

Mesossoma (Fig. 27). Dorso do tórax coriáceo, com uma fileira de pontuações paralelas à margem posterior do pronoto; disco pronotal 1,45 vezes mais longo do que mesoscuto; notáulices largas e completas, distantes 3 vezes sua largura posterior; sulcos parapsidais sinuosos e finos, incompletos anteriormente. Sulco escutelar profundo e largo com as extremidades pouco dilatadas e voltadas para trás. Disco propodeal 1,35 vezes mais largo do que longo, com 5 carenas discais, carena mediana completa, as demais incompletas, as paramedianas divergindo medianamente convergindo posteriormente, segundo par terminando logo após a região mediana, com carena adicional irregular entre a mediana e paramediana; carena lateral mais inferior do que a carena sublateral em perfil, formando uma cavidade alongada estriada; disco estriado, estrias laterais às carenas discais e sublaterais em maior quantidade e mais finas; cantos posteriores foveolados; declividade estrigulada com carena mediana; lateral do propódeo lineado. Mesopleura com fóvea superior fechada e alongada, fóvea inferior grande e fechada (Fig. 28). Tíbias pouco espinhosas. Fêmur anterior 2,27 vezes mais longo do que largo. Garras tarsais trífidas, dente basal arredondado, demais pontiagudos.

Material examinado. Holótipo: fêmea; BRASIL, Minas Gerais, Belo Horizonte, Estação Ecológica 1.XII.1996, armadilha Malaise, J.C.R. Fontenelle col. (UFMG).

Observações. Esta espécie é semelhante a $R$. (T.) subaenus Kieffer, 1906, mas apresenta uma série de diferenças que justificam considerá-la como nova. $R$. (T.) subaenus possui, carenas paramedianas paralelas à mediana, mandíbula grande com 4 dentes semifundidos, olhos alongados, fóvea superior da mesopleura longa e fina e fóvea inferior aberta. Enquanto esta espécie possui, carenas paramedianas divergindo medianamente e convergindo posteriormente, olhos não tão alongados, fóvea superior mais curta e fóvea inferior fechada. É conhecida apenas a partir do holótipo.

Epíteto específico refere-se ao fato das carenas paramedianas serem curvas.

\section{Rhabdepyris (Trichotepyris) foveaticeps sp. nov.} (Figs. 29-32)

Descrição. Macho, holótipo: LB 2,48 mm; LFW 1,3 mm.

Cor. Cabeça e Mesossoma pretos; metassoma e tégulas castanho-escuros, mandíbulas e antenas castanho-escuras; palpos castanho-claros; pernas castanho-escuras, tíbias e tarsos castanhos; asas anteriores hialinas; nervuras e estigma castanhos.

Cabeça (Fig. 29). Mandíbulas com dentes pequenos. Clípeo com lobo mediano angulado e muito grande, carena mediana evidente, alta e angulada vista em perfil, formando uma reentrância na região de contato com a fronte. Escrobo antenal não carenado. Razão entre os 4 primeiros artículos antenais 14:5:6:6. Olhos densamente pilosos, margeados por um conjunto de fóveas justapostas e fortes, exceto na porção anterior, tais fóveas acompanhadas externamente por uma carena especialmente conspícua na fronte. Fronte fortemente coriácea, pontuações pequenas, separadas 2-3 vezes seus diâmetros, com um sulco mediano foveolado entre o ocelo anterior e o clípeo. WH 1,04 X LH; WF 0,64 X WH; WF 1,33 X HE; OOL 0,80 X WOT, distância dos ocelos posterior à crista do vértice menor do que DAO. Vértice fracamente convexo, têmporas divergentes.

Mesossoma (Fig. 29). Dorso coriáceo como a fronte; disco pronotal 0,75 vezes mais longo do que mesoscuto, com uma fileira de fóveas alongadas na margem posterior; notáulices completas, largas e profundas até o ápice, distantes 3 vezes sua largura posterior; sulcos parapsidais retos e finos, incompletos anteriormente. Sulco escutelar profundo e largo 


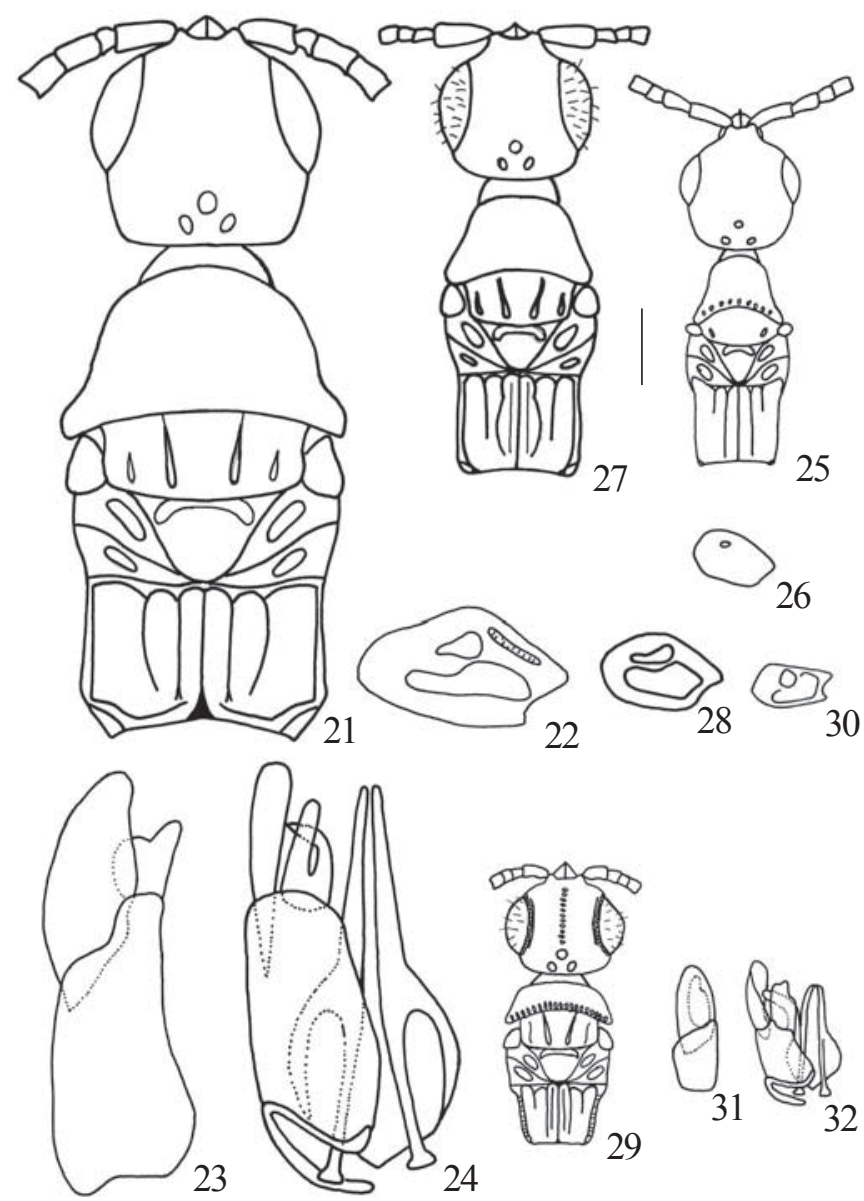

Figs. 21-32. 21-24, Rhabdepyris atlanticus: 21, holótipo macho, cabeça e Mesossoma, dorsal; 22, mesopleura, lateral; 23, genitália, lateral; 24, genitália, ventral; 25-26, Rhabdepyris areolatus: 25, holótipo fêmea, cabeça e Mesossoma, dorsal; 26, mesopleura, lateral; 27-28, Rhabdepyris curvicarinatus: 27, holótipo fêmea, cabeça e Mesossoma, dorsal; 28, mesopleura, lateral; 29-32, Rhabdepyris foveaticeps: 29, holótipo macho, cabeça e Mesossoma, dorsal; 30, mesopleura, lateral; 31, genitália, lateral; 32, genitália, ventral. (Escala figs. 21, 22, 25, 26, 27 e $28=0,25 \mathrm{~mm} ; 31$ e $32=0,32 \mathrm{~mm} ; 23,24,29$ e $30=155 \mu \mathrm{m})$.

com as extremidades pouco dilatadas. Disco propodeal 1,29 vezes mais largo do que longo, com 7 carenas discais, carena mediana completa, as demais incompletas, sendo que as mais laterais, ocupando apenas a metade anterior do disco; carena lateral mais inferior do que a carena sub-lateral em perfil, formando uma cavidade alongada estriada; disco estriado entre as carenas discais e estrigulado lateralmente; cantos posteriores foveolados; declividade estrigulada, com carena mediana; lateral do propódeo lineada. Mesopleura com fóvea superior arredondada, fóvea inferior grande, com a margem superior amplamente aberta (Fig. 30). Tíbia mediana espinhosa. Fêmur anterior 3,08 vezes mais longo do que largo.

Genitália (Fig. 31-32). Parâmeros largos com ápice arredondado, margens paralelas, base larga, obliqua e mais desenvolvida dorsalmente; volsela com cúspides grandes e mais baixas do que os parâmeros, escavadas ventralmente, dígitos mais curtos do que as cúspides, base dilatada e arredondada; edeago mais alto do que o dígito, apódemas dilatados.

Material examinado. Holótipo: $\sigma^{\pi}$; BRASIL, Paraná, Jundiaí do Sul, Fazenda Monte Verde 08.XII.1986, armadilha Malaise, Profaupar (DZUP)

Observações. Apresenta padrão único em Rhabdepyris, com um conjunto de fóveas justapostas acompanhando os olhos, exceto na região anterior, e outro conjunto de fóveas justapostas entre o ocelo anterior e o clípeo. É conhecido apenas a partir do holótipo.

Epíteto específico refere-se à presença de três conjuntos de fóveas justapostas na cabeça, sendo duas ao redor dos olhos e uma na região mediana.

\section{Rhabdepyris (Trichotepyris) cupreolus Evans, 1965}

Esta espécie era conhecida para o Brasil (Santa Catarina) e agora é citada pela primeira vez para Alagoas, Sergipe, Bahia e Minas Gerais. R. (T.) cupreolus é uma das cinco espécies do grupo pulchripennis, que apresenta entre outras características manchas escuras nas asas anteriores. Os dois exemplares da Bahia apresentam asas com tais manchas um pouco mais claras do que as do holótipo. O exemplar de Alagoas apresenta reflexos metálicos fortes e um tom de verde dourado, os exemplares da Bahia apresentam reflexos metálico fraco e um verde escuro, tendendo a preto, enquanto o restante apresenta reflexos metálicos verde oliva como no holótipo. Azevedo (1993) descreveu R. (T.) superpilosus que apresenta nove carenas discais e escrobo antenal carenado sendo a primeira espécie do grupo pulchripennis a apresentar tal característica. Entretanto após análise do holótipo, observouse que este também apresenta o escrobo antenal carenado não reportado em sua descrição original, triângulo ocelar compacto e presença de cinco carenas discais nítidas com quatro carenas fracas. Desta forma, é possível que $R$. (T.) superpilosus venha a ser considerada como $R$. (T.) cupreolus.

Material examinado. BRASIL, Alagoas, 1 , Quebrangulo, Reserva Biológica Pedra Talhada, 08-11.IX.2002, armadilha Möricke, PenteadoDias \& eq. col. (MZSP); Sergipe, 7 \%, Santa Maria do Itanhy, Crasto,

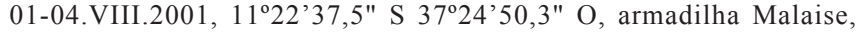
M.T. Tavares \& eq .col. (MZSP- UFES); Bahia, 1 + , Lençóis, 5.I.1992, armadilha Möricke, Azevedo col. (UFES); Minas Gerais, 1 ㅇ, Belo Horizonte, Estação Ecológica, 27.XI.1996, armadilha Malaise, J.C.R. Fontenelle col. (UFMG). Este material foi comparado com o holótipo fêmea do Brasil, Santa Catarina, Nova Teutônia (MCZH).

\section{Rhabdepyris (Trichotepyris) hirticulus Evans, 1965}

Esta espécie era conhecida para o Panamá e Brasil (São Paulo e Santa Catarina) e agora é citado pela primeira vez para Minas Gerais, Espírito Santo, Rio de Janeiro e Paraná.

Material examinado. BRASIL, Minas Gerais, 2 ㅇ, Belo Horizonte,Estação Ecológica, 25.XI.1996 e 2.XII.1996, armadilha Malaise, J.C.R. Fontenelle col. (UFMG); Espírito Santo, 1 우, Atílio 
Vivavcqua, Fazenda Oriente, 13-20.II.2003, 2058'38,6"S $41^{\circ} 10^{\prime} 10,6^{\prime \prime} \mathrm{O}$, armadilha Malaise, M.T. Tavares, C.O. Azevedo \& eq.col. (UFES); 1 ㅇ, Vila Velha, Reserva Jacarenema, 30.X.2002, armadilha Malaise, Azevedo \& eq. col (UFES); Rio de Janeiro, 1 ㅇ, Nova Iguaçu, Reserva Biológica do Tinguá, 5-8.III.2002 e 2 क , 8-11.III.2002, $22^{\circ} 34^{\prime} 30^{\prime \prime S} 43^{\circ} 26^{\prime} 08,4^{\prime \prime} \mathrm{O}$, armadilha Malaise, S.T.P. Amarante \& eq. col. (MZSP); 1 웅, Nova Iguaçu, Reserva Biológica do Tingua, 69.III.2002, $22^{\circ} 34^{\prime} 30^{\prime \prime S} 43^{\circ} 26^{\prime} 11^{\prime \prime}$ O, armadilha Möricke, S.T.P. Amarante \& eq. col. (MZSP); São Paulo, 1 †, Peruíbe, Estação

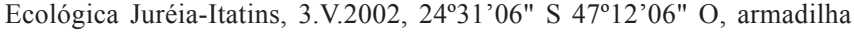
Malaise, N.W. Perioto \& eq. col. (MZSP); Paraná, 1 ㅇ, Jundiaí do Sul, Fazenda Monte Verde, 8.IX.1986, armadilha Malaise, Profaupar (DZUP). Este material foi comparado com o holótipo fêmea do Panamá, Canal Zone, Barro Colorado I (MCZH).

\section{Rhabdepyris (Trichotepyris) plaumanni Evans, 1965}

Esta espécie era conhecida a partir da série-tipo Brasil (Santa Catarina) e agora é citada pela primeira vez para o Paraná.

Material examinado. BRASIL, Paraná, 2 ㅇ, Jundiaí do Sul, Fazenda Monte Verde, 2.III.1987 e 14.IX.1987, armadilha Malaise, Profaupar (DZUP).

Observações. Evans (1965) descreveu o disco propodeal possuindo 7 carenas discais, sem mencionar seus formatos. Nesta série, disco propodeal com 5 carenas discais mais 2 falsas; apenas a carena mediana completa; segundo par convergindo posteriormente, quase tocando nas paramedianas.
Agradecimentos. Ao setor de Genética do Departamento de Biologia, UFES, pelo empréstimo da câmara clara, utilizada para ilustração da genitália, e ao programa BIOTA/FAPESP processo $n^{\circ}$ 98/05083-0, CNPq processo $n^{\circ} 469321 / 00-8$ pelo auxílio financeiro.Aos curadores listados em material examinado pelo empréstimo do material. Aos revisores pelas sugestões propostas.

\section{REFERÊNCIAS}

Azevedo, C. O. 1992a. On Rhabdepyris Kieffer (Hymenoptera, Bethylidae) in the area of São Carlos: I. Subgenus Rhabdepyris (Rhabdepyris). Revista Brasileira de Entomologia 36: 241244.

1992b. Sobre os Rhabdepyris Kieffer (Hymenoptera, Bethylidae) coletados em Piçarras, SC, Brasil. Revista Brasileira de Entomologia 36: 251-254.

1993. On Rhabdepyris Kieffer (Hymenoptera, Bethylidae) in the area of São Carlos, State of São Paulo, Brazil: II. Subgenus Trichotepyris. Revista Brasileira de Entomologia 37: 305-308. 1999. On the Neotropical Rhabdepyris Kieffer (Hymenoptera, Bethylidae) of the subgenus Chlorepyris. Revista Brasileira de Zoologia 16: 887-897.

Evans, H.E. 1964. A Synopsis of the American Bethylidae (Hymenoptera: Aculeata). Bulletin of the Museum of Comparative Zoology 132: $1-222$.

1965. A Revision of the Genus Rhabdepyris in the Americas (Hymenoptera: Bethylidae). Bulletin of the Museum of Comparative Zoology 133: 68-151.

Gordh, G. \& L. Moczar 1990. A catalog of the world Bethylidae (Hymenoptera). Memoirs of the American Entomological Institute 46: $1-364$.

Harris, R. A. 1979. A glossary of surface sculpturing. Occasional Papers on Entomology 28: 1-31. 